\title{
PELATIHAN PENGGUNAAN APLIKASI GEOGEBRA PADA PEMBELAJARAN MATERI TRANSFORMASI DI SMPN 2 GONDANG TULUNGAGUNG
}

\author{
Oleh: \\ Susanah ${ }^{1}$, Pradnyo Wijayanti², Rini Setianingsih ${ }^{3}$, Shofan Fiangga ${ }^{4}$ \\ 1,2,3,4Jurusan Matematika FMIPA Unesa \\ 4shofanfiangga@unesa.ac.id
}

\begin{abstract}
Abstrak
Salah satu materi mendasar dan baru pada Kurikulum 2013 adalah materi Tranformasi di jenjang SMP. Hal ini menuntut guru untuk kreatif dalam penyampaian materi tersebut sehingga siswa dapat memahami dengan baik. Salah satunya yaitu dengan penerapan program aplikasi GeoGebra dalam pembelajaran. Akan tetapi, masih banyak guru yang memiliki kesulitan dalam memanfaatkan aplikasi Geogebra ini. Lebih jauh lagi, kenyataan yang ada di SMPN 2 Gondang Tulungagung, guru-guru di SMPN 2 Gondang Tulungagung masih kesulitan dalam menggunakan media pembelajaran yang digunakan untuk menyampaikan materi pelajaran di kelas. Sehingga, diperlukan pelatihan penggunaan program GeoGebra dalam penyampaian materi Transformasi ini. Pelatihan ini bertujuan untuk membantu guru-guru SMPN 2 Gondang Tulungagung dalam mengembangkan kompetensi pedagogik guru dalam melaksanakan pembelajarannya. Pelatihan ini dilaksanakan dalam dua tahap. Tahap yang pertama adalah pemaparan dan sosialisasi penggunaan program GeoGebra. Tahap yang kedua adalah simulasi penggunaan program GeoGebra dalam penyampaian materi Transformasi. Peserta dibagi menjadi kelompok-kelompok kecil yang terdiri dari 4 sampai 5 orang untuk memilih materi yang akan disampaikan dengan menggunakan program GeoGebra. Pembuatan Media Pembelajaran yang dihasilkan oleh para peserta kemudian dievaluasi, apakah sudah sesuai dengan yang direncanakan. Evaluasi ini digunakan untuk mengukur kemampuan guru dalam menggunakan program GeoGebra dalam penyampaian materi Transformasi.
\end{abstract}

Kata Kunci: Aplikasi GeoGebra, Transformasi, Pembelajaran Matematika

\begin{abstract}
One of fundamental subject which is new in Kurikulum 2013 is Tranformation in middle school. This situation forces the teacher to creatively think how to teach the subject in order to make the students understand well. Using Geogebra as application in assisting the teaching of Transformation may be one of innovative approach. However, the number of teachers who are able to operate Geogebra is still limited. Furthermore, this situation can be seen in SMPN 2 Gondang Tulungagung where the teachers there are having difficulties in interacting with Mathematics software for mathematics teaching in the class. Therefore, a workshop to train the teacher in using Geogebra is needed. This training is aimed for assisting the teachers in SMPN 2 Gondang Tulungagung in developing their pedagogic competencies on the usage of Geogebra. The training is designed in two phases. The first stage is about the explanation about Geogebra and its properties. The next stage is a simulation workshop in using Geogebra for classroom teaching. The participants in the workshop is divided into groups to develop their own geogebra teaching materials. The materials are evaluated based on the learning outcome of the transformation subject. This evalution is used for measuring the teachers' ability in using Geogebra in delivering Transformation materials.
\end{abstract}

Keywords: GeoGebra Application, Transformation, Mathematics Teaching and Learning

\section{PENDAHULUAN}

Penyelenggaraan sebagaimana yang diamanatkan dalam Undang-undang Nomor 20 Tahun 2003 tentang Sistem Pendidikan Nasional diharapkan dapat mewujudkan proses berkembangnya kualitas pribadi peserta didik sebagai generasi penerus bangsa di masa depan (Depdikbud, 2003). Hal ini diyakini akan menjadi faktor determinan bagi tumbuh kembangnya bangsa dan negara Indonesia sepanjang zaman. Dari sekian banyak unsur sumber daya pendidikan, kurikulum 
merupakan salah satu unsur yang memberikan kontribusi yang signifikan untuk mewujudkan proses berkembangnya kualitas potensi peserta didik. Kurikulum sebagaimana yang ditegaskan dalam Pasal 1 Ayat (19) Undang-undang Nomor 20 Tahun 2003 adalah seperangkat rencana dan pengaturan mengenai tujuan, isi, dan bahan pelajaran serta cara yang digunakan sebagai pedoman penyelenggaraan kegiatan pembelajaran untuk mencapai tujuan pendidikan tertentu.

Sekolah Menengah Pertama Negeri 2 Gondang Tulungagung merupakan salah satu penyelenggara pendidikan. Untuk mewujudkan tujuan pendidikan, guru harus mampu mempersiapkan dan mengimplementasikan proses pembelajaran sesuai kurikulum yang berlaku dengan menggunakan sarana dan prasarana semaksimal mungkin. Oleh karena itu guruguru dituntut untuk sekreatif mungkin dalam mempersiapkan dan melaksanakan pembelajaran, sehingga, salah satu yang harus dimiliki guru adalah bagaimana memilih media yang dapat digunakan dalam pembelajaran matematika (Manoy, 2014). Sebagian besar guru-guru masih banyak yang belum terbiasa menggunakan media pembelajaran berbantuan aplikasi program komputer yang dapat meningkatkan pemahamannya terhadap suatu materi matematika, khususnya geometri (Heinich, 2002). Hal tersebut juga terjadi pada guruguru SMP di Tulungagung, khususnya di SMPN 2 Gondang Tulungagung.

Tenaga pengajar di Sekolah Menengah Pertama Negeri 2 Gondang Tulungagung terdiri dari guru-guru yang sudah berstatus pegawai negeri atau guru tetap dan guru-guru honorer. Apapun status guru yang mengajar di Sekolah Menengah Pertama Negeri 2 Gondang Tulungagung tersebut harus melaksanakan sesuai dengan kurikulum yang berlaku. Oleh karena itu, mereka harus dapat melaksanakan proses belajar mengajar sesuai dengan kurikulum yang berlaku yaitu kurikulum 2013, dan dapat sekreatif mungkin dalam melaksanakan proses pembelajaran di kelas. Akan tetapi, banyak guru mengalami kesulitan dalam menggunakan aplikasi komputer untuk mengajarkan materi geometri kepada siswanya. Pemilihan dan penggunaan media yang tepat dapat membuat siswa tertarik belajar geometri dan pada akhirnya dapat meningkatkan hasil belajar matematikanya (Ibrahim, 2001).
Salah satu aplikasi yang mudah untuk mengajarkan materi geometri adalah dengan GeoGebra atau WimGeom. Oleh karena itu, dari PKM ini diharapkan dapat membekali guru-guru tentang media dalam mengajarkan materi geometri.

Berdasarkan hasil observasi di Sekolah Menengah Pertama Negeri 2 Gondang Tulungagung, kegiatan pengabdian pada masyarakat ini bertujuan untuk mengetahui: (1) bagaimanakah semangat peserta dalam mengikuti proses pelatihan penggunaan program aplikasi GeoGebra/Wimgeom dalam pembelajaran matematika di Sekolah Menengah Pertama Negeri 2 Gondang Tulungagung, (2) apakah peserta dapat menggunakan program aplikasi GeoGebra/WimGeom dalam pembelajaran matematika, dan (3) bagaimana Respon peserta pelatihan penggunaan program aplikasi GeoGebra/Wimgeom dalam pembelajaran matematika di Sekolah Menengah Pertama Negeri 2 Gondang Tulungagung.

\section{METODE PELAKSANAAN}

\section{Kerangka Pemecahan Masalah}

Kerangka pemecahan masalah pada program PkM ini meliputi:

1. Paparan penggunanan aplikasi GeoGebra dalam pembelajaran matematika. Pada kegiatan ini dipaparkan dan diberi contoh cara penggunaan aplikasi GeoGebra/Wimgeom dalam pembelajaran matematika.

2. Simulasi penggunaan aplikasi GeoGebra dalam pembelajaran matematika. Pada kegiatan ini, guru dibagi dalam kelompokkelompok kecil (4-5 orang) untuk memilih dan menyimulasikan penggunaan aplikasi GeoGebra (Wimgeom) dalam pembelajaran matematika.

\section{Khalayak Sasaran Antara yang Strategis}

Khalayak sasaran antara yang strategis pada kegiatan ini Kepala Sekolah Menengah Pertama Negeri 2 Gondang Tulungagung. Sedang khalayak sasarannya adalah guruguru Sekolah Menengah Pertama Negeri 2 Gondang Tulungagung. Keterlibatan Kepala Sekolah diharapkan dapat mengawal keberlanjutan penerapan materi yang diperoleh pada kegiatan pelatihan ini.

\section{Keterkaitan}

Institusi yang terkait dalam kegiatan ini adalah sebagai berikut: 
1. Jurusan Matematika

Peran Jurusan Matematika adalah menyediakan 4 dosen sebagai nara sumber pada kegiatan pelatihan dan workshop. Manfaat yang diperoleh Jurusan Matematika sebagai media sosialisasi dan mendapat data (masukan) berkaitan dengan kondisi riil pembelajaran matematika khususnya di SMP

2. Sekolah Menengah Pertama Negeri 2 Gondang Tulungagung.

Sebagai lembaga tempat guru-guru bernaung yang memfasilitasi dan mengkoordinasi kegiatan ini dengan menyediakan tempat dan guru peserta pelatihan. Manfaat yang diperoleh Sekolah Menengah Pertama Negeri 2 Gondang Tulungagung adalah membantu guru dalam penggunaan program aplikasi GeoGebra/Wimgeom dalam pembelajaran matematika.

3. Lembaga Penelitian dan Pengabdian Masyarakat (LPPM) Unesa

LPPM berperan memberikan fasilitas guna terlaksananya kegiatan ini. LPPM juga memberikan legalitas terhadap kegiatan ini.

4. Fakultas MIPA Unesa

Fakultas MIPA berperan dalam memotivasi dan memberi ijin pada dosennya untuk melaksanakan kegiatan ini.

5. Unesa

Sebagai lembaga, Unesa memberi ruang dan ijin bagi dosennya untuk melaksanakan kegiatan pengabdian pada masyarakat ini.

\section{Metode Kegiatan}

Metode yang digunakan untuk mencapai tujuan kegiatan ini adalah dengan mengadakan kegiatan pelatihan penggunaan program aplikasi Geogebra/WimGeom dalam pembelajaran matematika Sekolah Menengah Pertama Negeri 2 Gondang Tulungagung.

1. Pemaparan penggunaan program aplikasi Geogebra/WimGeom dalam pembelajaran matematika.

2. Simulasi penggunaan program aplikasi Geogebra/WimGeom dalam pembelajaran matematika.

\section{Rancangan Evaluasi}

berikut.

Evaluasi dilakukan dengan cara sebagai

1. Memberikan angket kepada peserta setelah pemaparan penggunaan program aplikasi Geogebra/WimGeom dalam pembelajaran matematika.

2. Mengoreksi hasil penggunaan program aplikasi Geogebra/WimGeom dalam pembelajaran matematika.

3. Memberikan angket setelah keseluruhan kegiatan berakhir.

Kegiatan ini dikatakan berhasil jika memenuhi kriteria berikut:

1. Peserta memberikan respon positif terhadap pemaparan penggunaan program aplikasi Geogebra/WimGeom dalam pembelajaran matematika.

2. Materi yang dipilih umtuk disimulasikan dalam pembelajaran yang disusun peserta minimal berkategori cukup.

3. Respon peserta terhadap pelaksanaan kegiatan baik

\section{HASIL DAN PEMBAHASAN}

Kegiatan pelatihan ini dilakukan selama 1 (satu) hari yaitu tanggal 5 Agustus 2017, bertempat di gedung SMPN 2 Gondang, Tulungagung. Adapun hasil yang diperoleh dapat dituangkan dalam bentuk hasil kegiatan pada setiap tahap pelaksanaan sebagai berikut.

\section{Perencanaan}

Kegiatan-kegiatan yang dilakukan pada tahap perencanaan adalah sebagai berikut.

1. Sosialisasi kegiatan PKM di sekolah mitra (khalayak sasaran)

Sosialisasi dilakukan pada bulan April 2017 dalam bentuk rapat koordinasi dengan mengundang semua guru di sekolah mitra berkenaan dengan kegiatan PKM yang akan dilaksanakan.

2. Penyusunan program pelatihan

Berdasarkan hasil identifikasi, hasil analisis permasalahan yang ada, dan hasil analisis kebutuhan, selanjutnya disusun program pelatihan. Pelaksanaan pelatihan dilakukan selama 1 (satu) kali tatap muka, dengan mengundang guru-guru di SMPN 2 Gondang dan sekolah lainnya dalam lingkup MGMP Matematika Kecamatan Gondang, Tulungagung.

\section{Pelaksanaan Tindakan}

1. Paparan tentang Aplikasi Geogebra/Wimgeom oleh Tim PKM

Pelatihan ini diikuti oleh 32 guru matematika tingkat SMP di Kecamatan Gondang Tulungagung. Guru-guru 
tersebut tergabung dalam MGMP kota Tulungagung.

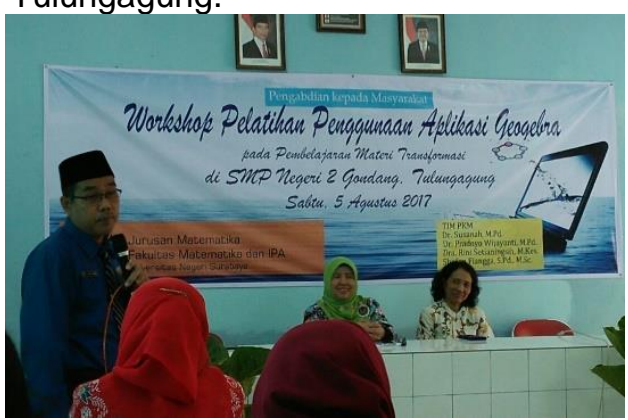

(a)

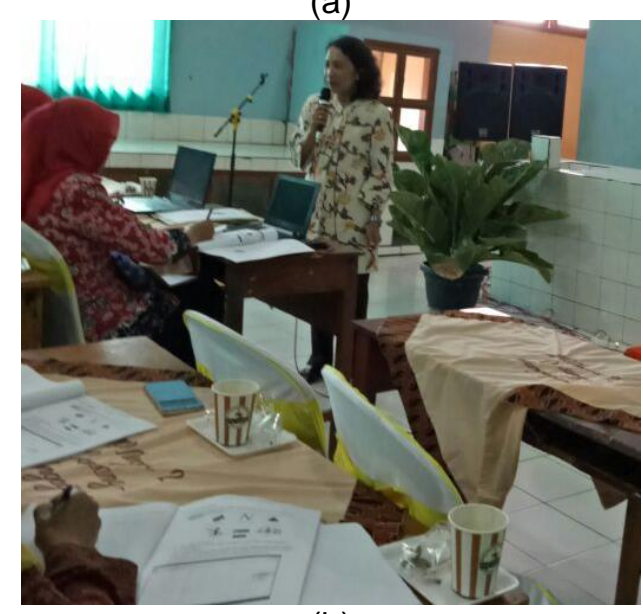

(b)

Gambar 1, Pemaparan materi oleh Tim PKM

2. Simulasi dan Pendampingan Penggunaan Aplikasi Geogebra/Wimgeom dalam pembelajaran Matematika.

Pada kegiatan ini, peserta pelatihan dibagi dalam beberapa kelompok dan diberi tugas untuk berlatih menggunakan aplikasi Geogebra. Kegiatan ini dipandu oleh Tim PKM. Produk dari kegiatan ini adalah Jasa Pelatihan Penggunaan
Aplikasi Geogebra dalam Pembalajaran Matematika.

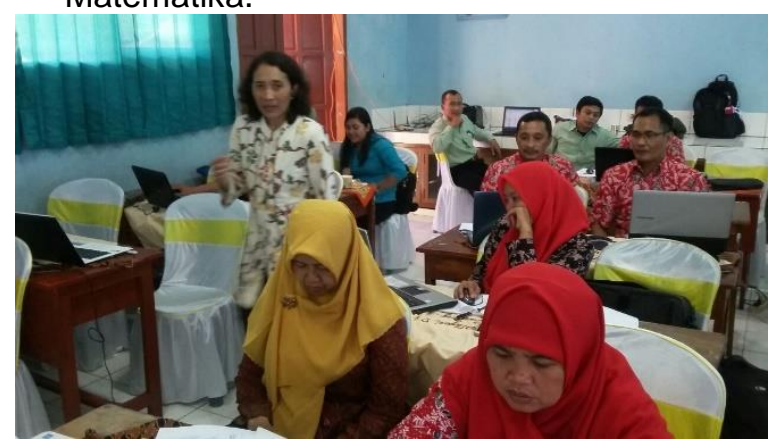

(a)

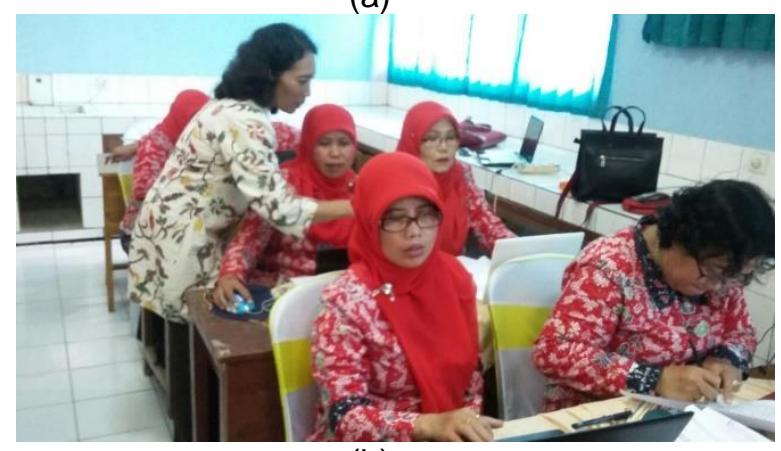

(b)

Gambar 2, Simulasi dan pendampingan

\section{Evaluasi}

Evaluasi dilakukan terhadap seluruh rangkaian kegiatan PKM dengan menggunakan angket yang dibagikan kepada seluruh peserta pelatihan.

Adapun jadwal kegiatannya ada pada tabel 1.

Tabel 1 Jadwal Kegiatan

\begin{tabular}{lll}
\hline Hari, Tanggal & Pukul & Acara \\
\hline Sabtu, & $08.00-08.30$ & Registrasi dan Persiapan \\
\cline { 2 - 3 } 5 Agustus 2015 & $08.30-09.00$ & Pembukaan \\
\cline { 2 - 3 } & $09.00-10.00$ & $\begin{array}{l}\text { Paparan tentang aplikasi Geogebra dan } \\
\text { penggunaannya dalam pembelajaran } \\
\text { matematika. }\end{array}$ \\
\cline { 2 - 3 } & & $\begin{array}{l}\text { Simulasi dan pendampingan penggunaan } \\
\text { Geogebra dalam mengajar matematika di } \\
\text { SMP. }\end{array}$ \\
\hline $10.00-12.00$ & \begin{tabular}{l} 
Ishoma \\
\hline $12.00-13.00$
\end{tabular} & $\begin{array}{l}\text { Lanjutan simulasi dan pendampingan } \\
\text { penggunaan Geogebra dalam mengajar } \\
\text { matematika di SMP. }\end{array}$ \\
\hline $12.30-15.00$ & Coffee break \\
\hline $15.00-15.30$ & Penutupan dan foto bersama \\
\hline $15.30-16.00$ &
\end{tabular}




\section{Pembahasan}

Pelaksanaan workshop pemantapan kemampuan guru MTs di Tulungagung dalam melakukan penilaian hasil belajar ini dievaluasi berdasarkan respon peserta terhadap pertanyaan dalam angket yang disusun oleh tim pelaksana tentang pelaksanaan pelatihan. Secara umum peserta merespon positif terhadap pelaksanaan kegiatan pelatihan aplikasi Geogebra ini. Beberapa hal yang dikemukakan peserta berkenaan dengan "positifnya" kegiatan ini adalah:

1. Sebanyak 12 peserta (80\%) menyatakan bahwa kegiatan pemantapan ini "Bermanfaat" atau 'Sangat Bermanfaat" bagi pembelajaran matematika dengan menggunakan IT (12 org), dan sebanyak 3 peserta (20\%) mengatakan bahwa kegiatan ini "Sangat bermanfaat" untuk membantu guru membuat soal/gambar matematika.

2. Menurut peserta, hal positif yang dapat diambil dari kegiatan workshop ini adalah Merupakan ilmu baru untuk membuat media pembelajaran (8 orang atau $53,33 \%$ ) dan dapat mengaplikasikan pada pembuatan perangkat ( 7 orang atau $46,67 \%$ )

3. Hal-hal yang membedakan kegiatan workshop ini dengan kegiatan workshop yang pernah diikuti peserta sebelumnya adalah:

- Langsung praktek (6 org)

- Adanya tutorial yang jelas pada workshop ini (5 org)

- Pemandunya enak (4 orang)

- Tidak ada pre-post test

4. Kegiatan yang diinginkan peserta berkenaan dengan peningkatan kualitas Guru:

- Kegiatan workshop aplikasi yang berkelanjutan (11 orang atau 68,75\%)

- Ingin tambah waktu sehingga banyak materi yang diperoleh (2 orang atau $12,5 \%)$

- Ingin workshop lainnya yang mendukung profesi guru (karya tulis dII) (3 orang $4,8 \%$ )

5. Berikan saran berkaitan dengan kegiatan workshop ini, khususnya dalam hal materi workshop, waktu pelaksanaan, narasumber, dan tindak lanjut.

- Materi workshop bagus dan perlu ditambah, waktunya kurang, narasumber sabar dan jelas dalam menyampaikan (6 orang)

- Sebaiknya diadakan lagi (8 orang)

- Dibuatkan LKS (1 orang)

Berdasarkan jawaban peserta dalam angket, berarti indikator keberhasilan pelaksanaan PKM terpenuhi. Oleh karena itu, dapat disimpulkan bahwa kegiatan PKM ini berhasil mencapai tujuan yang ditetapkan.

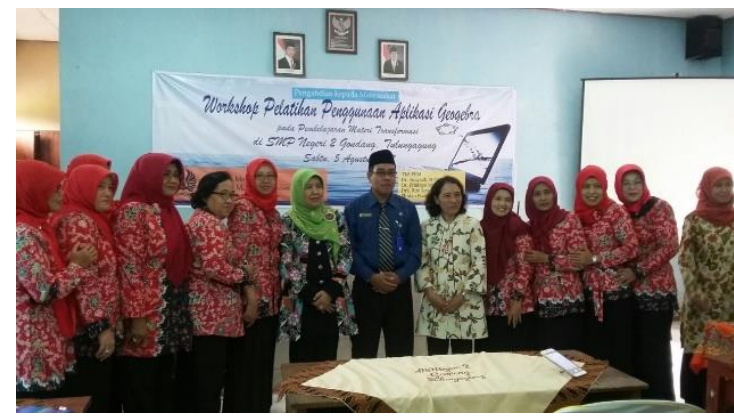

Gambar 2, Simulasi dan pendampingan

\section{SIMPULAN DAN SARAN}

\section{Simpulan}

Berdasarkan hasil dan pembahasan yang disajikan pada bab sebelumnya, untuk pelaksanaan kegiatan PKM ini dapat dikemukakan simpulan sebagai berikut. Secara umum, para peserta memberi respons positif terhadap pelaksanaan kegiatan pelatihan penggunaan aplikasi Geogebra dalam pembelajaran matematika. Beberapa hal yang dikemukakan peserta berkenaan dengan "positifnya" kegiatan ini adalah: (1) Sebanyak 12 peserta (80\%) menyatakan bahwa kegiatan pemantapan ini 'Sangat Bermanfaat" atau "Bermanfaat"; (2) Dapat membantu guru membuat soal/gambar matematika; (3) Penjelasan yang diberikan oleh nara sumber sangat detail dan jelas; Merupakan ilmu baru untuk membuat media pembelajaran (8 org); (3) Langsung praktik, (4) Adanya tutorial yang jelas pada workshop ini (5 org). (5) Hendaknya sering dilakukan pelatihan semacam ini dengan waktu yang cukup lama agar guru semakin terampil menggunakan aplikasi Geogebra.

\section{Saran}

Secara umum, dalam rangka peningkatan profesionalitas guru, dan secara khusus 
dalam rangka meningkatkan kemampuan guru dalam menggunakan aplikasi Geogebra, pada masa mendatang, kegiatan pemantapan dan workshop semacam ini hendaknya dapat mengakomodasi harapan peserta, yang antara lain sebagai berikut:

1. Perlu tindak lanjut,

2. Waktunya perlu ditambah lagi,

3. Materi dibuat lebih menyenangkan,

4. Tidak berbelit-belit pelaksanaan ditambah, materi menarik.

5. Diberikan tidak hanya sehari,

\section{DAFTAR PUSTAKA}

Depdikbud (2003). Undang-undang Nomor 20 Tahun 2003 tentang Sistem Pendidikan Nasional.

Heinich, R., Molenda, M., Russell, J. D., \& Smaldino, S.E. 2002. Instructional media and technology for learning, 7 th edition. New Jersey: Prentice Hall, Inc.

Ibrahim, H. 1997. Pemanfaatan dan pengembangan media slide pembelajaran. Bahan ajar. Disajikan dalam pelatihan produksi dan penggunaan media pembelajaran bagi dosen MDU Universitas Negeri Malang, 8 Februari s.d 6 Maret 1999.
6. Pelaksanaannya kalau bisa tiap tahun

7. Pelaksanaannya kalau bisa berkelanjutan

8. Dibuatkan lembar kerja workshop agar lebih mudah mengikuti

9. Workshop lebih direncanakan dengan

10. Pemateri ditambah agar mencakup seluruh peserta workshop

11. Narasumbernya sudah cukup telaten dan menyenangkan

12. Alokasi waktu untuk workshop ditambah

Ibrahim, H., Sihkabuden, Suprijanta, \& Kustiawan, U. 2001. Media pembelajaran : Bahan sajian program pendidikan akta mengajar. FIP. UM.

Manoy, Trineke. J, (2014) Modul Alat Peraga Dalam Pembelajaran Matematika, Strategi Pembelajan Matematika, Universitas Terbuka, Jakarta

Pujiati, 2004, Penggunaan Alat Peraga Dalam Pembelajaran Matematika SMP, Depdiknas, PPPG Matematika Yogjakarta, Yogjakarta 